\title{
LA SITUACIÓN ECONÓMICA DE LA AUDIENCIA DE QUITO DURANTE LA SEGUNDA MITAD DEL SIGLO XVIII
}

\author{
Agueda Rivera Garrido \\ Escuela de Estudios Hispano-Americanos. Sevilla. España.
}

La situación desoladora en la que se ve abocada la Audiencia de Quito en el siglo XVIII se ha atribuido tradicionalmente a la libertad de comercio decretada en 1778 que provocó la entrada masiva de mercancías europeas y que trajo como consecuencia la ruina de la industria textil serrana. Sin embargo, esta crisis económica no debe atribuirse sólo a esta nueva reglamentación para el comercio, sino que es una realidad desde principios del siglo XVIII según los autores coetáneos ${ }^{1}$.

Los quiteños, durante todo el siglo XVIII, fueron consciente del repliegue económico que estaban sufriendo y del que intentarán salir en una serie continuada de esfuerzos que no llegaron a culminar sus expectativas.

En 1720, el obispo de Quito describe la situación de decadencia en que se haya el comercio, sobre todo de paños, de esta capital, provocado por la competencia de textiles extranjeros. Crisis que dos años más tarde amplía a todo el territorio de la Audiencia, que adquiere una nueva fisonomía con sus calles llenas de mendigos blancos, mestizos, indios y negros ${ }^{2}$.

Muchas fueron las quejas que los quiteños remitieron a las autoridades, dando cuenta de la lamentable situación económica en la que se hallaba esta Audiencia. En una carta mandada por don Miguel de Gijón y León, diputado del cabildo al Rey, solicita la rebaja de los censos del cinco al tres por ciento, aduciendo la precariedad económica de estas provincias, que si bien habían gozado de una gran riqueza dada la exuberancia de sus frutos y cosechas 
y sobre todo de la fábrica de paños, esta situación cambió radicalmente, los campos se esterilizaron y los paños sufrieron las consecuencias de la entrada masiva de los europeos. Todo ello ha llevado a la ciudad a la más lamentable ruina, por lo que los hacendados se veían obligados a vender o a sacar a subasta pública sus propiedades cargadas de hipoteca a un precio menor del que valían, e incluso a abandonarlas antes de que comiencen las diligencias judiciales ${ }^{3}$.

Es indudable que desde que el comercio francés comenzó a penetrar por el Cabo de Hornos, Quito perdió gran parte de las ventajas para la exportación de sus manufacturas textiles al cono sur, pues el trato mercantil se meridionalizó centrándose más en los tejidos extranjeros. Si a ello añadimos el cese de las ferias de Portobelo en 1737, los puertos de esta Audiencia quedaron al margen de la ruta principal de comercio, pues fueron los géneros que entraban por el Cabo de Hornos los que masivamente inundaron el Perú, Charcas y otras zonas de Río de la Plata y Chile, donde tradicionalmente eran llevados los paños quiteños ${ }^{4}$.

En relación con lo anteriormente expuesto, el marqués de Maenza como procurador de la ciudad de Quito informa al rey que el comercio de esta provincia se basaba principalmente en el producto de sus fábricas de paños, comercio que ha quedado prácticamente inexistente por la abundancia de ropas procedentes de Europa. Para constatarlo afirma lo siguiente:

"el comercio por Buenos Aires (...) y los franceses consiguieron permiso para hacerlo por el Cabo de Hornos en las costas del Mar del Sur, se llenaron aquellos Reinos de tantas mercaderías de Europa que su misma copia produjo la suma baja de precios y causó la desestimación y pérdida casi total de aquellos obrajes de la tierra (...) y de los que únicamente dependía su comercio y subsistencia (...) de doce mil fardos de pafios que antiguamente se extralan para los reinos del Perú a más de treinta anios que sólo ha salido tres mil"'.

Las consecuencias inmediatas serán el descenso de los paños quiteños y el declive de los obrajes. En Quito capital existían once obrajes, de los cuales entre 1768 y 1775 solamente dos permanecen en funcionamiento. En el corregimiento estaban empadronados 14 obrajes, de los cuales sólo desaparecen 4, siguiendo en activo los 10 restantes. En total deja de funcionar un $52 \%$ más notorio en la ciudad que cierra un $81,81 \%$ que en el campo, donde representan un $28,57 \%$. Respecto a otros establecimientos también se ven afectados por la crisis, las sombrererías de Quito que de 34 del total un $89,47 \%$ había cerrado por diferentes motivos. Los tejares eran 8 en la capital, de los cuales para estas fechas sólo 3 permanecen abiertos. De las 20 ollerías de Quito, sólo 1 permanecía en funcionamiento. Las restantes o habían cerrado o estaban arruinadas. En la misma lamentosa situación se encuentran las pulperias y tiendas ${ }^{6}$. 
A todo ello hay que añadir la falta de moneda circulante, no sólo debido al cese de las ferias de Portobelo, sino también a la extracción anual de los situados que eran remitidos a las plazas de Santa Marta y Cartagena, por lo que la situación fue empeorándose progresivamente.

Esta crisis que también afectó a Guayaquil, estuvo provocada por la prohibición del comercio del cacao que este puerto mantenía con México, ya que fue clausurado en beneficio del de Venezuela, país este último que monopolizó el comercio de este producto hasta 1789 , año en que se concede a Guayaquil libertad de comercio para la exportación de cacao a Acapulco. Indudablemente, la decadencia económica de la Audiencia no sólo se concentró en la crisis del comercio de paños, sino que también se extendió a la agricultura, ya que se sucedieron años de sequía con otros de lluvias continuas que repercutió en la producción de las haciendas, cuyas cosechas no aportaban lo suficiente para el pago de las obligaciones anuales, sin olvidar que en muchas de ellas pesaban censos y deudas.

A todo ello hay que añadir una larga sucesión de desgracias de origen natural que se producen a lo largo de todo el siglo XVIII. Los terremotos y erupciones causaron graves daños: en 1704 se produjo un terremoto que asoló el área del Pichincha; otro en 1740, pero fue sin duda el de 1755 el que más daño causó sobre todo en la ciudad de Quito y en sus alrededores. En 1757 se repetía el seísmo, afectando de forma muy grave al territorio de Latacunga donde poco después se presentó una epidemia de peste causando la mortandad de muchas personas.

En 1768 fue el Cotopaxi el que entró en erupción, cubriendo con polvo volcánico muchas leguas a la redonda, lo que provocó la esterilización de los campos y por consiguiente la falta de pasto para alimento del ganado. Lo mismo ocurrió en 1773 con la erupción del Tungurahua que llenó de ceniza los campos?.

Si el terremoto de 1778 fue importante, mucho más lo fue el que se produjo en 1797 que afectó de norte a sur, es decir, de Popayán a Loja, destruyendo muchas ciudades y villas, como Latacunga, Ambato y Riobamba entre otras, y ocasionando varios miles de muertos. Según un informe del presidente Muñoz de Guzmán se puede contabilizar un total de 12.553 personas a las que habría que añadir las que perecieron en poblados y lugares dispersos por lo que no sería exagerado afirmar que el número de muertos ascendiera a $16.000^{8}$.

En 1785 la ciudad de Quito sufrió una grave epidemia de sarampión, si bien esta epidemia asoló primeramente a la capital, pronto se propagó por el resto de las provincias de la Audiencia. Ante esta situación y debido a la falta de médicos que auxiliaran a los moradores de los restantes territorios, el 
presidente decretó que se formulase una instrucción clara y extensa sobre lo que debía hacerse según lo efectuado en Quito, y que proporcionó los mayores alivios. Así pues, esta instrucción se remitió a todos los gobernadores, corregidores, tenientes y curas para que se ocupasen del cuidado y manutención de los enfermos, pues se temía que los estragos de esta epidemia fueran mayores aun en estas zonas desprotegidas que los ocasionados en la capital, donde según los datos recogidos de las parroquias, Hospital de Belén, conventos y monasterios, se calculó que habían perecido en Quito capital 1.050 personas, entre ellas 434 adultos y 616 niños?

Si tenemos en cuenta los desastres anteriormente enunciados, nos podemos hacer una idea bastante aproximada de las desgracias que progresivamente se sucedieron en el territorio de la Audiencia. Situación lamentable que se vio refrendada por el informe que el presidente don José García León y Pizarro envió al ministro Gálvez el 18 de junio de 1779 en el cual describe cómo se encontraban estas provincias, tanto las de la Sierra como las de Guayaquil, donde todo "es una continua permuta de frutos por frutos y efectos por efectos" 10 .

Este informe de León y Pizarro viene corroborado doce años más tarde por el entonces presidente de esta Audiencia don Juan Antonio Mon y Velarde, quien afirma:

"que en el curso de estos doce anios, no se ha fomentado ningún ramo de industria; no se ha facilitado ninguna extracción de frutos, por el contrario la cascarilla o quina de Loja se ha reducido a estanco y está severamente prohibida su saca: el cacao de Guayaquil estuvo mucho tiempo reducido (...). Es cierto que con motivo de la guerra logró esta provincia algún alivio, pues habiendo escaseado los paños de Europa tuvieron alguna salida los del Pais; pero esa momentánea y fugaz gloria pasó como un relámpago que desapareciendo hace más sensible la oscuridad" ".

Para salir de la crisis propone restablecer la fábrica de textiles, la cría de ganado lanar además de la explotación de las ricas minas de oro y plata que contiene este territorio, tal y como se habla efectuado en otras zonas americanas como México ${ }^{12}$.

\section{1.-ESTRUCTURA DE PRODUCCIÓN DE LA SIERRA}

Este epígrafe lo hemos estructurado atendiendo a las diferentes zonas geográficas que marcan muy directamente las pautas de la Audiencia. 


\section{1.-Sierra Nor-Central}

La opinión de los especialistas en la historia del Ecuador colonial es prácticamente unánime al afirmar que la segunda mitad del siglo XVIII representa una época de grave crisis en la industria textil de la Sierra, sobre todo Nor-Central, lo que provocó un desequilibrio económico y social que afectó a todas las regiones. Esta crisis que ya comienza en los primeros años del siglo XVIII parece motivada por el descalabro en la producción del centro minero de Potosí, lo que obliga a una orientación de la producción textil al mercado neogranadino. Otra causa que afectó a este ramo manufacturero fue la entrada masiva de textiles europeos que competían en calidad y precio con los elaborados en los obrajes de esta zona. Ahora bien, según Marchán Romero es un error hablar de crisis, pues afirma que lo que se produce es un recorte en la producción. Insiste además en que "el mercado interno de la Sierra norcentral no sólo que no se retrotrae, sino que durante la fase 1760-1820 acelera su crecimiento (...); su expansión obedece a su vinculación a los mercados guayaquileños y colombianos" 13 .

Esta crisis o decaimiento obligó a esta zona a centrar la producción de la hacienda en invertir en aquellos negocios que le aportaran más ganancias y que lógicamente estaría destinado a aquellos grupos sociales que tuvieran el suficiente poder adquisitivo para pagarlos, fuera de satisfacer las necesidades de consumo del resto de la población. De ahí la dicotomía existente entre una gran masa de población que vive en la más indigente situación frente a la preponderancia económica de un reducido número de hacendados.

Dentro de este espacio geográfico de la Sierra Nor-Central hay que distinguir la zona norte, cuya estructura de producción es la hacienda-industria, destinada a la fabricación de panegas, azúcar y aguardiente, lo que determina su especialización en productos derivados de la caña de azúcar. Esta, aunque menos rentable que la diversificación e introducción de otros ramos, convierte el complejo hacienda-industria en la principal fuente de riqueza para esta zona norte ${ }^{14}$.

La sierra central engloba su estructura productiva en el complejo hacienda-obraje, lo que conduce a una especialización lanar del campo. Característica principal del siglo XVIII es que predominan los obrajes de propietarios particulares que "forman un todo orgánico con la bacienda" 15 .

Ateniéndonos a la Sierra Central se puede afirmar que el panorama que presentaba la región era de grandes propiedades que rodeaban a los núcleos urbanos, siendo las pequeñas y medianas parcelas prácticamente inexistentes. Estas grandes haciendas dependían de un importante número de mano de obra que eran subsanadas por el indígena, que al verse privado por otras for- 
mas de supervivencia tuvo que someterse al dominio de estos grandes terratenientes.

La hacienda, además de grandes propiedades de terreno, y de una fuerza de trabajo servil, a diferencia de la hacienda-industria, su producción se caracterizaba por una diversificación de sus actividades económicas, no sólo las tradicionales agropecuarias, sino también la elaboración de sus propios productos especialmente textiles $u$ otros de forma que tienden a una monopolización tanto del producto y del mercado, así como de la mano de obra que le lleva al dominio de su zona de influencia ${ }^{16}$.

La mayor parte de su producción era principalmente la textil, elaborada en sus obrajes, cuya principal fuente de mano de obra fue el concertaje. En cuanto a la distribución del trabajo dentro del obraje, éste se realizaba diariamente enviando al indígena a la zona donde correspondía según las tareas que tenía que realizar. Teniendo en cuenta que prácticamente no existía maquinaria, el trabajo que realizaba el indio era manual, pasando el proceso de producción por diferentes etapas hasta llegar a su acabado final, lo que aportaba un bajo nivel de rendimiento producto-mano de obra empleada ${ }^{17}$.

Aunque legalmente el concertaje estipulaba un sueldo al indígena, prácticamente éste nunca lo recibía, debido a anticipos que pedía, descuentos de su tributo personal, contribuciones a la iglesia, vestidos y alimentos que la misma hacienda vendía al concertado, multas por no cumplir con la tarea asignada, pérdida de animales, etc. Aun así, a finales de la colonia el indio prefería incorporarse a la hacienda-obraje, principalmente por el progresivo desmembramiento de la comunidad indígena que había perdido todo su papel en la legitimidad de las autoridades étnicas, hecho que incitó a que la población tributaria tendiera a individualizarse, saliendo de los confines comunales en busca de un trabajo remunerado mediante el concertaje ${ }^{18}$.

Es indudable que la situación de la Sierra norcentral fue afectada por la crisis, sobre todo en lo referente al ramo textil. Ahora bien, su apertura a nuevas redes comerciales con el norte, actualmente Colombia, le permitió mantener unos mínimos niveles de producción con los que subsistir decorosamente, máxime cuando la posesión de tierras era para la élite blanca que habitaba en esta zona, símbolo de prestigio social.

Se puede afirmar que en lo referente al complejo hacienda-industria, ésta subsiste gracias a la producción de aguardiente y azúcar, que comercializan en el mercado interno de la región. Respecto a la hacienda-obraje, ésta se diversifica y complementa a finales del siglo XVIII, sobre todo a raíz del auge cacaotero de Guayaquil, proyectando sus productos predominantemente textiles a "Colombia, mientras que los sembrios agricolas se encaminan a las ciudades de Quito y Guayaquil" "?. 


\section{2.-Sierra Sur.}

Comúnmente la crisis que afecta a la Audiencia de Quito durante el siglo XVIII y principalmente a la Sierra también se ha extendido a la Sierra Sur, cuyo principal centro está localizado en Cuenca. Estudios posteriores han dado como resultado opiniones distintas que defienden que esta zona escapa a la crisis generalizada, debido principalmente al bajo costo de su producción textil que si bien es de ínfima calidad no pierde por ello el mercado peruano, además de otros productos que esta zona genera como por ejemplo la cascarilla o quina, que le permiten mantener una cierta actividad comercial con la que subsanar la crítica situación económica por la que pasa la Audiencia en estas fechas.

Los resultados a los que Silvia Palomeque llega a través de su trabajo sobre la historia económica de Cuenca son principalmente dos: "el primero, que se debe considerar incorrecto hacer la crisis de Quito extensiva a esta zona; el segundo, que para estas fechas se rompe con la imagen de especialización agricola de la región, como abastecedora de granos y harinas a Guayaquil, pues ya a finales del siglo XVII esta zona despunta por su especialización textil algodonera destinada principalmente a Lambayeque y Lima, mientras que Guayaquil queda como puerto adonde va dirigida una parte de la cascarilla y de donde se traen productos introducidos en él' 20 .

La estructura de producción se basa en la hacienda, donde la tenencia de la tierra, el control de la mano de obra y el nivel tecnológico de su producción agrícola era comparable al resto de la Sierra. Sin embargo, en esta zona sur hay una mayor fragmentación de la propiedad rural y un predominio de sistemas de tenencia diversos. El tamaño de la hacienda tendía a ser más pequeño, apareciendo propiedades medianas y pequeñas en manos de blancos y mestizos y pequeños arrendatarios que cultivaban por cuenta propia en tierras públicas ${ }^{21}$.

Esta situación particular que se presentaba en el austro estaba motivada por la relativa intensidad del movimiento comercial, sobre todo a finales del siglo XVIII, y que "influyd para que la polarización de la propiedad de la tierra no fuera tan extrema como la zona central y norte donde el proceso de consolidación territorial habia seguido otras matrices" ${ }^{22}$.

Entre las producciones más importantes destacan la agrícola y ganadera. Entre las primeras están el maíz, el trigo y la caña de azúcar. El trigo destinado al consumo local es cultivado en haciendas ya sean grandes o medianas y cuya mano de obra es el concertaje. La caña de azúcar abastece al mercado local y sus excedentes se exportan a otros espacios. Este producto se utiliza tanto para la fabricación de aguardientes como de raspaduras, pues el azúcar era de uso exclusivo de la clase dominante ${ }^{23}$. 
La producción ganadera es importante en ovinos, bovinos, caballar y mular. Hay que destacar que en muchas haciendas se combina la producción agrícola con la cría de ganado. Los productos de estas haciendas estaban destinados principalmente al mercado y una parte de ellos al consumo local. Aunque en ocasiones se exportan a Guayaquil y Quito, el mercado más importante se encuentra en la región misma, consumidos por los parceleros que no cubren sus necesidades con la labor de sus propias tierras cuyos productos prácticamente no se comercializan y son utilizados para sustento de las familias.

Estos problemas con que se encuentra la hacienda desde el decaimiento de la economía alta peruana las ha abocado "no al mentado cierre total dentro de sus economias, sino a una reducción de la circulación a regiones más pequeñas y a sectores económicos menos dinámicos" 24.

De gran importancia económica que prácticamente la salva de la crisis es la producción textil y artesanal. Especializada en tocuyos de muy baja calidad, pero también de un mínimo coste de producción hacen que esta elaboración mantenga un mercado donde venderlos en competencia con los textiles europeos. Estos tejidos, tocuyos y lienzos de algodón, a diferencia de la Sierra Nor-Central no se fabrican en obrajes, sino en una pequeña industria doméstica en la que principalmente opera la mujer del parcelero, aunque también intervenga la población indígena, los mestizos y blancos pobres. Estos tejidos se destinan principalmente a Lima, Guayaquil, Chile y norte de Perú. Otros textiles como medias, calcetines y calcetas tienen como mercado Lima y Guayaquil. Comercio que prácticamente monopoliza los mercaderes de la Carrera de Lima que organizan para su beneficio la comunicación entre estos diferentes espacios ${ }^{25}$.

Otro producto importante dentro del comercio exportador de Cuenca es la cascarilla o quina que se recolectaba directamente del árbol que la producía y que se encontraba en los declives de las cordilleras, especialmente en Cuenca y Loja que las convierte en las principales zonas de recolección de esta corteza medicinal. De hecho, en Cuenca su cosecha y posterior venta convierten a este producto en un importante eje de la actividad económica desde fines del siglo XVIII y comienzos del XIX, pues la cascarilla significaba una de las principales fuentes de ingreso para los hacendados, quienes normalmente comercializaban ellos mismos su producto, aunque también existían comerciantes intermediarios especializados ${ }^{26}$.

Existen dos tipos de montes, los "acotados" y los de libre extracción. Los primeros dependen de la Corona, mientras que los segundos se encuentran en haciendas y su recolección está a cargo del terrateniente. Esta extrac- 
ción se efectuaba cuando surgía algún pedido, entonces se contrataba la mano de obra que normalmente eran indios y blancos de las inmediaciones ${ }^{27}$.

El circuito que sigue este producto una vez recogida la cáscara que cubre la corteza del árbol es llevarla a las haciendas o a la ciudad, y una vez seleccionadas es enviada al puerto de Guayaquil, Tumbes o Paita para exportarla a Lima y desde allí a España. Debido a su masiva extracción sin control alguno para esta época "los montes de Loja se encuentran casi agotados y en los de Cuenca hay que retirarse cinco o seis dias, a pie, para encontrarla; esto encarece su extracción" ${ }^{28}$.

\section{2.-Desarrollo y auge del litoral}

La situación geográfica de Guayaquil y su puerto la convierten en una zona de gran importancia en cuanto al control mercantil del Pacífico se refiere, pues era la puerta de entrada para la mayor parte de los productos destinados a la zona del interior de la Audiencia, así como al Perú y Nueva España ya que es paso forzoso para su comunicación. A esta circunstancia hay que añadir la importancia de su astillero, debido a la abundancia de maderas de gran calidad, importancia que destacan Jorge Juan y Antonio de Ulloa cuando lo describen como "el único donde se puede construir navios grandes para guerras o para comercios, como también el más propio para carenar, cuyas circunstancias no las gozan otros puertos de astillero que hay en las costas de Chile o en la de los reinos de Nueva España" ${ }^{29}$.

La relación entre su situación geográfica y su desarrollo económico puede llevarnos a pensar erróneamente que esta situación privilegiada benefició a dicha zona durante toda la colonia. Ello no es así, dada la política restrictiva de la metrópoli que perduró hasta el último tercio del siglo XVIII.

Prácticamente durante los siglos XVI y XVII no existían plantaciones ni cultivos de importancia, tanto para el mercado externo o interno y su tierra permanecía en manos de campesinos. Así en la zona costera, Manabí y Santa Elena, los españoles se dedicaban a la explotación de la sal, mientras que los indígenas y mestizos vivían de la pesca y del cultivo que realizaban en parcelas libremente ${ }^{30}$.

La zona del río Daule, aunque se caracterizó por la pequeña y mediana propiedad, también conoció haciendas de considerable extensión. Esta zona fue elegida por la Corona para el cultivo del tabaco que compraba a los campesinos, lo que favoreció la consolidación de la pequeña propiedad.

La zona occidental del Guayas en el interior, y el litoral sur fueron pobladas hasta el siglo XVIII por medianos y pequeños productores. Fue esta 
zona donde a partir de 1765 se convirtió en la gran productora de cacao, dando como resultado la llegada de inmigrantes procedentes sobre todo de la Sierra y el proceso de concentración de la tierra ${ }^{31}$.

Aunque es evidente que durante la colonia la provincia contó con los mismos recursos y posibilidades, no es hasta el último tercio del siglo XVIII que la situación cambie y ello es debido sin duda alguna al apoyo de la metrópoli, basado en las reformas borbónicas. La situación de depresión o de escaso progreso que caracteriza la primera mitad del siglo sólo ofrece sus consecuencias a partir de 1779 , con la política borbónica, logrando una importante resonancia gracias a las medidas adoptadas como son: la liberalización del comercio, la reducción de los derechos de almojarifazgo, la eliminación total de los aranceles para las remesas de mercancías dirigidas a España y la disminución de intereses que pesaban sobre los censos. A esto hay que añadir la promoción de las huertas de cacao, tabaco y caña. Sobre todo es de destacar el aumento de las exportaciones de cacao que continúa siendo exportado para México con un 55\%, mientras que para España sólo llega a un $8,4 \%$. Situación que cambia conforme nos acercamos al siglo XIX que es cuando la metrópoli se convierte en el principal centro de consumo del mercado guayaquileño ${ }^{32}$.

Hemos visto cómo durante la colonia y parte del siglo XVIII el sistema de tenencia de la tierra estaba estructurado en medianas y pequeñas parcelas, pero a raíz del boom cacaotero de 1774 esta estructura cambia. Debido a las importantes redes fluviales de esta zona, las primeras propiedades se establecieron a lo largo de las riberas de los ríos y van a ser éstas las que se constituyan en los núcleos de expansión territorial que dio lugar a latifundios cada vez mayores. Esta ampliación de la propiedad se hizo a base de denuncias "de tierras baldias colindantes con el núcleo original o a través de la apropiación por subterfugios legales de las propiedades de pequeños labradores con titulos mal asentados 0 de comunidades indígenas" ${ }^{33}$.

Hay que destacar que aunque los grandes latifundios son los que imperan en esta época también siguieron subsistiendo propiedades medianas y pequeñas cuya producción era muy diversificada y cuyos excedentes se vendían en el mercado, tales como las hortalizas, plátanos, arroz, caña de azúcar, etcétera.

Debido a la expansión del cultivo del cacao y a los grandes latifundios que ello generó, se produjo una demanda de mano de obra de la que esta zona carecía. Las oleadas de inmigrantes llegados de otros territorios, sobre todo de la Sierra unido a la abundancia de tierras disponibles derivó en una alteración en las relaciones salariales. Esta relación trabajo-salario se debió principalmente a lo remunerativo de los precios y las exportaciones destina- 
das a un mercado mundial en expansión y a la competencia de los dueños de las plantaciones para traer mano de obra, lo que trajo consigo un alza en los salarios. Jornales que para algunos hacendados eran desorbitados pero que se tenían que acoplar a ellos debido a las condiciones del mercado del trabajo. Así pues, para principios del siglo XIX el jornal de un trabajador en el cacao durante seis horas era de seis reales más la comida, lo que significaba "entre diez y treinta veces más de lo que se pagaba a un peón serrano" ${ }^{34}$.

Con el objetivo de presentar un panorama más completo de la economía de esta zona vamos a hacer un breve resumen de sus principales productos de exportación, basándonos en la obra de María Luisa Laviana Cuetos donde se realiza un estudio exhaustivo y detallado del Guayaquil del siglo XVIII, de sus recursos naturales y de su desarrollo económico.

Lo primero que nos encontramos es que el cacao se convierte en el motor de la economía guayaquileña en el último cuarto del siglo XVIII, centrándose su cultivo en el partido de Baba, Palenque, Babahoyo y Machala. La liberalización que se produce de este producto en competencia del cacao caraqueño comienza en 1774 , pasándose de una producción de 50.000 cargas en 1770 a casi 200.000 hacia 1820 , lo que significa un incremento alrededor del $300 \%$. Hay que tener en cuenta las fluctuaciones en el precio de las cargas que se producen a lo largo de estas fechas ${ }^{35}$.

La madera ocupa el segundo lugar en las exportaciones guayaquileñas, debido principalmente a la abundancia de este producto como a su calidad y variedad, a lo que hay que añadir la facilidad de explotación y transporte utilizando la gran cantidad de redes fluviales que cubre el territorio. Su tala era prácticamente libre, debido principalmente a la exhuberancia forestal de sus bosques. En un intento de controlar esta situación, la Corona a principios de siglo decide estancar el monte Bulubulu, único productor importante de palo maría. Esta medida, en algunas ocasiones perjudicial y en otras beneficiosa para la Real Hacienda, llevó a don José García de León y Pizarro a establecer unas ordenanzas que regulasen la explotación maderera de la península. Estas nuevas normativas provocaron la reacción contraria de los más importantes guayaquileños, e incluso el mismo cabildo tomó parte activa en estas protestas, por lo que la explotación maderera siguió siendo una actividad incontrolada ${ }^{36}$.

Otro producto de importancia en estas exportaciones es el tabaco, sin embargo, su evolución es diferente a la del cacao ya que este producto se ordena estancar en 1778 , lo que influyó negativamente en su cultivo y propició su decadencia. Así pues, para 1730, el corregimiento de Guayaquil producía 185.000 mazos de tabaco al año. En 1754 se registra una producción de 100.000 mazos, producciones que varían a lo largo de los tres pri- 
meros tercios del siglo XVIII, pero al estancarse decae significativamente y a principios del siglo XIX ya no representa una importante fuente de ingresos para la Real Hacienda ${ }^{37}$.

La caña de azúcar, producto que si bien no estaba destinado a la exportación, alcanzó un importante papel en la industria guayaquileña a raíz de la creación en 1778 del estanco de aguardiente, lo que impulsó la producción de este producto. Sin embargo, durante todo el siglo XVIII el azúcar que se producía en la región del Daule no subsanaba las exigencias de los guayaquileños que no dejaron de importarla durante toda esta centuria. Lo que si se produjo fue un aumento considerable de estas plantaciones a partir de la creación del mencionado estanco, dedicado a la elaboración de la miel que será transformada en aguardiente blanco, anisete, mistela o ron que son las cuatro clases de aguardiente de caña que producía el estanco ${ }^{38}$.

Otros productos que se pueden destacar son los alimenticios, los plátanos, fríjoles, maíz, arroz, etc., pero que en modo alguno cubrían las necesidades de los guayaquileños que se veĺan obligados a importarlos del Perú. Entre los cultivos textiles destacan el algodón que se exportaba a Quito y el índigo del que se podía obtener tintas muy buenas. También tienen relevancia el cultivo del café, la zarzaparrilla, la pita, la cabuya, etcétera ${ }^{39}$.

En cuanto a la ganadería, ésta ocupa un lugar secundario si lo comparamos con el desarrollo agrícola. Sin embargo, permite a Guayaquil autoabastecerse de carne, principalmente vacuna, aunque hay abundante ganado caballar y en menor escala mular y de cerdo ${ }^{40}$.

\section{NOTAS}

1 Juan, Jorge y Antonio de Ulloa,Noticias secretas de América, 2 vols.,Madrid, 1982; Marqués de Selva Alegre, "En razón que cerca del Estado y gobierno político y militar de las provincias, ciudades, villas y lugares de la Audiencia de Quito, dada por su presidente el Marqués de Selva Alegre al virrey del Nuevo Reino de Granada", Quito, 13 de septiembre de 1754. Recogido en Arbitraje de límites entre Perú y el Ecuador. Documentos anexos al alegato de Perú.Tomo I, Madrid, 1905. págs. 138-169. Dionisio Alsedo y Herrera, Descripción geográfica de la Real Audiencia de Quito, Madrid, 1915. Descripción de las ciudades, villas y pueblos de los estados de Quito, Quito, 14 de junio de 1755, en Arbitraje de límites..., tomo III, Madrid, 1905, págs. 46- 52. F. J. Eugenio Santa Cruz y Espejo, "Voto de un ministro togado de la Audiencia de Quito" en Biblioteca Ecuatoriana Mínima, tomo xi, (Quito, 1960), págs.215-226. Pilar Ponce Leiva. "Relaciones histórico-geográficas de la Audiencia de Quito (siglos XVI-XIX)", vol. 30. tomo II, Madrid, 1992.

2 Ortiz de la Tabla Ducasse, Javier: "El obraje colonial ecuatoriano. Apraximación a su estudio" en Revista de Indias, núms. 149-150 (Madrid, 1977), págs. 471-541. Nuestra referencia corresponde a las págs. 531-532. 
3 Carta de don Miguel de Jijón y León al Rey [1754]. En A.G.I., Quito 139, folios 335vto-336. En una carta acompañada de Testimonio de Autos, el presidente don Dionisio Alsedo y Herrera informa al Rey que la mala gestión en el cobro de los diferentes ramos de Real Hacienda que suponen un débito de 399.396 pesos, es debido principalmente a la independencia de los oficiales reales de la Audiencia y del gobernador. Por lo que remite en Testimonio de Autos lo que ha efectuado para que el Ramo de Alcabalas y los oficios vendibles y renunciables salgan a subasta pública. Por tanto, parece contradecir el informe anterior, pues no achaca las deudas a la mala situación económica del territorio, sino a la mala gestión de los subalternos. En Carta del presidente don Dionisio de Alsedo y Herrera al Rey a la que acompaña Testimonio de Autos. Quito, 15 de mayo de 1731, folios 671-671vto.

4 Ramos Pérez, Demetrio: Entre el Plata y Bogotd. Cuatro claves de la emancipación ecuatoriana, Madrid, 1978, págs. 107-108.

5 Informe del marqués de Maenza en nombre de la ciudad al Rey [1752], en A.G.I., Quito, 139, folios 351-352.

6 Ortiz de la Tabla Ducasse: "Panorama económico y social del corregimiento de Quito (1768-1775)" en Revista de Indias, núms. 145-146 (Madrid, 1976), págs. 83-98. Nuestra referencia corresponde a las págs. 95-98.

7 González Suárez, Federico: Historia general de la república del Ecuador. Quito, 1970, págs. $1185-1192$.

8 Razón General de las Personas que han muerto... hecha por don Luis Mufioz de Guzmán, Quito, 20 de noviembre de 1797, A.G.I., Quito-403.

9 Carta del presidente don Juan José Villalengua a don José de Gálvez, Quito, 18 de octubre de 1785 , $n^{\circ}$ 628, A.G.I., Quito-243.

10 Ramos Pérez, op. cit., págs. 107-112.

11 Carta del presidente don Juan Antonio Mon y Velarde a don Antonio Valdes y Bazán, Quito, 18 de junio de 1790, n 4, A.G.I., Quito-545.

12 Ibidem.

Esta misma situación de penuria económica la encontramos en un carta que remite el presidente Barón de Carondelet, fechada en 1800, en la que afirma que la causa de esta situación se debe principalmente a la decadencia de sus manufacturas como consecuencia del comercio libre y a la mala administración llevada a cabo por algunos representantes legales. A ello hay que añadir la falta total de caudales, debido principalmente a los situados que se remiten a Cartagena y Santa Marta a las que se han destinado de 250.000 a 300.000 pesos en plata, cuando apenas han entrado por el comercio exterior 80.000 pesos. Todo ello unido a la devastación que originó el terremoto de 1797. Carta del presidente Barón de Carondelet a don Mariano Urquijo. Quito, 21 de noviembre de $1800, n^{\circ} 1$, A.G.I., Quito-548.

13 Marchán Romero, Carlos: "El sistema hacendario serrano, movilidad y cambio agrario" en Revista Cultura, vol. VII, no 19 (Quito, mayo-agosto de 1984), págs. 63-106. Nuestra referencia corresponde a las págs. 83-84.

14 Ibídem., pág. 86.

15 Ibídem., págs. 86-87.

16 Nick Mills y Gonzalo Ortiz: "Economla y sociedad en el Ecuador poscolonial. 1759-1859" en Cultura, Revista del Banco Central de Canadá, vol. II, nº (Quito, 1980), págs. 71-152. Nuestra referencia corresponde a la pág. 112.

17 Ibídem., pág. 113.

18 Mills, Nick D. y Gonzalo Ortiz, art. cit., págs. 114-115.

19 Marchán Romero, "El sistema hacendario...", art. cit., págs. 91-92. 
20 Palomeque, Silvia: "Historia económica de Cuenca y sus relaciones regionales (1). (Desde fines del siglo XVII a principios del XIX)" en Revista del Archivo Nacional de Historia. Sección del Azuay, $n^{\circ} 1$ (Cuenca-Ecuador, 1979),págs. 104-261. Nuestra referencia corresponde a las págs. 105-106.

21 Mills, "Economía y sociedad en el Ecuador poscolonial...", art. cit., pág. 117.

22 Mills, "Economia y sociedad en el Ecuador poscoloniah..", art. cit., pág. 118.

23 Palomeque, art. cit., págs. 113-114.

24 Ibídem., págs. 112-117.

25 Ibidem., págs. 118-124.

26 Mills, "Economia y sociedad en el Ecuador poscolonial..", art. cit., pág. 87.

27 Palomeque, art. cit., pág. 127.

28 Ibldem., págs. 126-127.

29 Ramos Gómez, Luis J.: Epoca, Génesis y Textos de las 'Noticias secretas de América', de Jorge Juan y Antonio de Ulloa, tomo II, Madrid, 1985, pág. 65.

30 Ibldem., págs. 219-220.

31 Arias, Hugo: "La economía de la Real Audiencia de Quito y la crisis del siglo XVIII" en Nueva Historia del Ecuador, vol. IV, Quito, 1989, págs. 219-220.

32 Marchán Romero, C.: "Economia y sociedad durante el siglo XVII" en Revista Cultura, vol. VIII, no 24a (Quito, enero-abril de 1986), págs. 55-76. Nuestra referencia corresponde a las págs. 6061.

33 Mills, "Economia y sociedad en el Ecuador poscolonial...", art. cit., pág. 107.

34 Ibídem., págs. 108-109.

35 Marla Luisa Laviana Cuetos, Guayaquil en el siglo XVII. Recursos naturales y desarrollo económico, Sevilla, 1987, págs. 177-180.

36 Ibídem., págs. 229-243.

37 Ibidem., págs. 190-194.

38 Ibldem., págs. 205-209.

39 Ibidem., págs. 209-216.

40 Ibidem., págs. 219-223. 